\title{
Study on the Influence of Accounting Computerization on Accounting Development
}

\author{
Ping LV
}

Shandong University of Finance and Economics, Jinan, Shandong, 250014

Keywords: Accounting Computerization, Accounting Development, Influence Study

\begin{abstract}
In the process of business management, accounting for financial management issues, accounting work can play a key role. In recent years, China's scientific and technological level of continuous improvement and the extensive application of computer technology, have promoted the development of accounting work, both gradually to the direction of computerized accounting development. Accounting work to achieve computerized accounting can be an effective combination of information technology and electronic technology, and can greatly enhance the level of accounting and accounting management level, which to some extent, the impact of accounting work.
\end{abstract}

\section{Introduction}

For the understanding of computerized accounting, mainly from the perspective of modern information technology analysis, into the modern technical characteristics, through the specific mode of financial management, and better promote the development of computerized accounting. Accounting computerization is an accounting information system implemented by an electronic computer. It realizes the automation of data processing, and makes the development of traditional manual accounting information system evolve into computerized accounting information system. The development of computerized accounting is the modernization of various financial conditions, information management, is the current financial system reform and development of the inevitable product, not only reduces the financial staff workload and work intensity, but also improve the accounting Accuracy, timeliness and integrity, and the formation of mutual cooperation, mutual supervision of the various information systems management, improve the efficiency of the financial sector, but also increased the transparency of financial management. So accounting computerization in the realization of network management and resource sharing has a significant impact.

\section{The Impact of Accounting Computerization on Accounting}

First of all, accounting computerization will have an impact on the management of accounting, the original accounting work, the need for staff to spend a lot of time and effort to carry out the corresponding accounting work, which led to the level of accounting management has not been effectively improved. The accounting work after the implementation of computerized accounting, its efficiency is effectively improved, and accounting a lot of data related information can be directly through the computerized system directly to the record, analysis and summary, and can use the information system for its fast delivery, And thus make full use of accounting data, so that staff can have more time and energy on the management work, to promote a major change in accounting management.

It is followed by the accounting work accounting rules of the impact of the previous accounting work by way of manual accounting, and the details of the account also made a clear requirement to require the use of loose-leaf accounts, general ledger need to use the book. Manual accounting in the voucher book in the recording process, the error occurs when the use of red crossed to correct the law and the write-off method to be corrected, can not be separated from the industry or blank line to record. In the implementation of accounting computerization, you can directly use the computer to automatically form a report, the books can be directly printed out, binding into the loose-leaf book, the use of computerized accounting system, the staff only need to enter the 
accounting voucher, the system will Automatically generate reports, not only can save more time, but also to improve work efficiency, in addition, the accounting computerization can also be efficient to complete a variety of auxiliary accounts, accurately reflect the current business situation, if an error, Directly with the original error certificate to its write-off, so that the accounting work becomes more simple.

There is the accounting work will be the form of accounting impact, the original accounting work, the staff need to pass the original certificate to record the contents of the voucher, and then through the contents of the record of its detailed accounts and general ledger registration , This is a more complex process. And in order to make the billing work simpler, the staff often will be copied, so there are some limitations. However, after the implementation of computerized accounting, it can effectively solve such problems, not only to avoid duplication of staff staff to the situation, but also to the maximum extent possible to reduce the low accounting vouchers wrong situation, in addition to , The implementation of the use of computerized accounting, but also to regulate the accounting vouchers, with the accounting system in the relevant system to make the credentials set, if there is illegal credential input, the computer system can automatically identify and refuse Re-input, and thus make the voucher more accurate, true, standardized.

\section{Computerized Development of the Main Problems in the Current Operation}

The development of accounting computerization is to solve the complicated and complicated problems of financial work, and it has high accuracy and timeliness. Therefore, it is necessary to have a strong understanding. Some enterprises are aware of the computerization of computerized accounting. Not enough, there is no accounting computerized management applied to every detail of the financial management, stay in the manual operation, superficial understanding on the basis of financial management, did not really play the role of accounting computerization.

Operator awareness of confidentiality is likely to cause huge losses, which is mainly due to improper operation authority set, operation and management lax. The actual work due to improper operation authority and password is not strict or did not do the special person dedicated to the accounting responsibility caused by accidents have occurred. Especially with the development of computer networks, due to any access to the Internet or download the virus intrusion and hacker attacks, resulting in system crashes and network paralysis cases are more and more.

In the accounting computerization of modern technology applications, the need for timely follow-up of software, accounting software applications often encounter some details, in order to prevent data loss, while the backup also makes a lot of hospitals can not give up manual Accounting, which in turn increased the burden of work. If you encounter some after-sales service is not timely software company, then the accounting computerization process will be greatly slowed down.

\section{Recommendations for Computerized Accounting}

Although the accounting work after the implementation of computerized accounting, can bring more impact, such as can improve the efficiency of the staff to enhance the level of business management and so on. But it also needs to develop a set of management and control measures in order to ensure the safety of accounting data.

First, we should strengthen the control of the organization. The goal of organizational information control is to reduce the incidence of fraud and error as much as possible. It is necessary for the system developers to divide the responsibilities reasonably. For example, the system developers can not participate in the system management work. The operator can not directly open the data file, modify and delete the relevant data and so on. Do a good job of system management and control, is to establish a sound responsibility system based on the key, but also the computerized work carried out smoothly.

The first point should be done to do the management of hardware facilities, the engine room to keep clean, to achieve fire, anti-theft, moisture, radiation and temperature standards; to prevent a sudden power outage caused by loss of data information should be equipped with the appropriate 
Supply of power; is strictly prohibited without any authorized personnel to operate the machine room, and the computer hardware equipment for regular maintenance, prohibit the use of foreign disk, to avoid the computer system infected with the virus. In order to ensure the standardization and continuity of accounting information processing, it is necessary to establish a multi-machine hot backup system. In order to effectively ensure the security of the network system, it should enhance the network system event response, intrusion detection and accident recovery control. The second point should be good software and data control security work. In order to avoid the illegal deletion and modification of the software and related accounting data, the security and reliability of the software and accounting data should be ensured, and the encryption technology should be used to ensure that the accounting data transmission and storage are very complete. The accounting information backup works well, if the accounting data is damaged, you can use the backup to restore it to the previous state.

There is the day-to-day operation and management should be constantly strengthened. Establish and improve the corresponding management system, the operator to strengthen management. Operators need to have good professionalism and professional ethics, and also have a certain sense of security and sense of responsibility. The operator needs to establish a sound management system, including the selection of screening, security checks and education and training, through a variety of ways to reduce due to human error caused by improper operation, triggering unnecessary errors in the operating system, and then bring unnecessary risks And so on; At the same time should also establish a system of access to the operating system, the identity of the user to identify, identify the user's identity and security level, and the specific access to the object were defined; the operation of the recording system to further improve, The system operation of the user identity, system parameters and operating time to record and monitor.

\section{Conclusion}

Management and other aspects of in-depth analysis of the gradual formation of the case library for the business to be carried out by the securities companies learn from. Enterprise asset securitization business simulation exercise is an attempt, but also to be carried out in the business of securities companies in front of a new topic. It is a virtual form of experience to accumulate the way. In the simulation exercise, the company can predict the problem and development.

\section{References}

[1] Yao Jianhua. Analysis of China's accounting computerization in the development of the problems and countermeasures [J]. Technology horizon, 2016 (02)

[2] Zhao Shu, Han Yue. Restricted the development of China's accounting computerization of the causes and countermeasures [J]. Brand, 2015 (11)

[3] Zhang Liru. Problems and Solutions in the Development of Accounting Computerization [J]. Inner Mongolia Science and Technology and Economy, 2016 (15)

[4] Tian $\mathrm{Xu}$. China's accounting computerization in the development of the problems and countermeasures [J]. Management Manager, 2015 (10)

[5] Chen Xuedong. Accounting computerization development needs attention [J]. Modern economic information, 2013 (24) 